9. Курьянова, Т. С. Культурное наследие: смысловое поле и практика.-Текст: непосредственный // Вестник Томского государственного университета. - 2011. - № 2. - С. 12-18.

10. Любичанковский. А. В. Методологический анализ формально юридического подхода к пониманию культурного наследия. - Текст : непосредственный // Вестник Оренбургского государственного университета. 2011. - № 4. - С. 140-146.

11. Никитина, Ю. А. Международные отношения и мировая политика: введение в специальность; учеб. пособие. - 2-е изд., испр. и доп. - Текст : непосредственный. - Москва : Аспект Пресс, 2012. - 151 с.

12. Кругликова, Г. А. Сохранение культурного наследия как фактор социального здоровья нации. - Текст : электронный // Социальная работа на Урале: исторический опыт и современность : межвуз. сб. науч. тр. Екатеринбург : Изд-во Рос. гос. проф.-пед. ун-та, 2003. - Вып. 3. - URL: http://do.teleclinica.ru/184727 (дата обращения 07.04.2019).

13. Евдокимов В. В. Международная практика и новые тенденции сохранения культурного наследия в условиях глобализации / В. В. Евдокимов, О. С. Вишнёва. - Текст : электронный // Вестник Карашандинского государственного университета. - 2009. - URL: http://articlekz.com/article/4534 (дата обращения: 07.04.2019).

14. Полякова, М. А. «Культурное наследие»: историческая динамика понятия.-Текст : электронный // Российский комитет программы ЮНЕСКО «Информация для всех»: [сайт]. - URL: http://www.ifapcom.ru/files/Monitoring/poljakova_kult_nasl_historical.pdf (дата обращения 07.04.2019).

Viktor A. Livtsov, Dr. of Historical Sciences, Professor Russian Presidential Academy of National Economy and Public Administration, Central Russian institute of Administration, Branch Office (Oryol, Russia) livcov@orel.ranepa.ru

Roman A. Bogatyryov

Russian Presidential Academy of National Economy and Public Administration, Central Russian institute of Administration, Branch Office (Oryol, Russia) romanbogatyryow@yandex.ru

\title{
CONSERVATION OF CULTURAL HERITAGE IN LONG-TERM GROWTH OF RUSSIA'S TERRITORIES
}

\begin{abstract}
The article briefly describes an evolution of public initiatives in sphere of conservation of cultural heritage into establishment of research institutes and international organizations for uncovering, listing and studying objects of historical and cultural heritage, and appearance of government agencies with executive powers work on matters of commercialization of these objects through integrating them into touristic sphere. Also, the paper outlines comparative characteristic of effectiveness of recovering objects of historical and cultural heritage in various territories of Russia.

Key words: cultural heritage, historical and cultural heritage, domestic tourism in Russia, All-Russian Society for the Preservation of Historical and Cultural Monuments, International Council on Monuments and Sites (ICOMOS).
\end{abstract}

УДК 17.023.32:159.953.2

DOI: $10.32340 / 2414-9101-2019-2-33-38$

О. В. Первушина, кандидат культурологии, доцент Алтайский государственный институт культуры (Барнаул, Россия) agaki-pervushina@yandexs.ru

\section{КУЛЬТУРНАЯ ПАМЯТЬ: ПРОБЛЕМНОЕ ПОЛЕ ИССЛЕДОВАНИЯ}

Аннотация. Представлен сравнительный анализ взглядов крупнейших отечественных и европейских историков культуры, социологов, семиологов, культурологов XIX и XX веков на феномен культурной памяти как устойчивое явление общественной жизни, представляющей собой специфический знаково-символический конструкт с собственной структурой, законами динамики и селективными механизмами. Охарактеризованы господствующие в гуманитарных и обществоведческих науках подходы к интерпретации понятия «культурная память», изложены пояснения о соотношении содержания понятия с дефинициями «индивидуальная память» и «коллективная память». 
Представлен перечень крупных проблемных областей научного изучения феномена культурной памяти, требующих внимания исследователей.

Ключевые слова: культурная память, коллективная память, индивидуальная память, культурная традиция, преемственность, традиционная культура, знаково-символический конструкт, текст.

В пространстве интенсивно изменяющейся, отличающейся высокой степенью динамизма современной инновационной культуре, вектор которой устремлён в будущее, устойчивой становится полярная тенденция - интерес к категориям измерения прошлого: «коллективная память», «воспоминание», «забвение», «след», «архаизация», «традиция», «неотрадиция». Значимое прошлое, воплощенное в традиционном, рассматривается как неотъемлемый элемент жизнедеятельности человеческого сообщества, его развития и устойчивости. Соответствующий межпредметный дискурс в зарубежной и отечественной гуманитаристике формировался на протяжении последних столетий. Научный интерес к проблеме исследования «памяти» в различных областях знания, в настоящее время, имеет устойчивую тенденцию к возрастанию. Складывается новая парадигма в области социальногуманитарных и культурологических исследований, которая не исчерпывается анализом на основе привычных дихотомий: традиция/новация, память/забвение, архаический/современный; имеют место новые подходы, которые отличает синтез данных понятий, их сочетание, которое проявляется в таких категориях как «культурная память», «социальная память», «коллективная память», «индивидульная память», «этнокультурная память». В рамках нашего исследования мы обратимся к категории «культурная память», так как данное понятие связано со всеми выше перечисленными категориями, требует уточнения и выявления комплекса проблем с ним связанных.

Наиболее крупные исследования, направленные на осмысление данного феномена, принадлежат французскому социологу Морису Хальбваксу и немецкому историку культуры Яну Ассману $[1,2]$. М. Хальбвакс рассматривает проблему памяти не только как чисто индивидуальный процесс (психологического и культурного) сохранения, обработки и воспроизводства индивидом полученных впечатлений, но в большей степени как результат и специфическую форму бытия коллективного сознания. Его подход основан на известной концепции «коллективного сознания» французского социолога Э. Дюркгейма. «Коллективное сознание» Э. Дюркгейм рассматривает как основу устойчивого существования общества, так как оно представляет собой систему надындивидуальных мировоззренческих смыслов [3]. Религиозные практики, миф, традиция - все это формы устойчивого коллективного опыта, которые определяют существование поколений во времени и пространстве, позволяя воспроизводить нечто неизмеримо большее, чем воля и смыслы, утверждаемые отдельным индивидом. Специфика подхода М. Хальбвакса базируется на этом основании, т. е. заключается в интерпретации памяти как социально обусловленного явления. Память - не просто воспроизводство, но и воссоздание прошлого (частичное или целостное), ориентиры для которого определяет общество. И если индивид воссоздает, реконструирует прошлое, он это совершает не только как индивидуальный психологический акт, а как член определённой группы, которая и определяет рамки воспоминаний. Как пишет М. Хальбвакс, при обращении к исследованиям «...по психологии, трактующих о памяти, вызывает большое удивление, что человек рассматривается в них как изолированное существо. Возможно, для понимания наших психологических операций и необходимо на первом этапе изучать лишь индивида, отсекая все его связи с обществом ему подобных. Однако свои воспоминания человек, как правило, приобретает, воссоздаёт в памяти, узнает и локализирует именно в обществе» $[1$, с. 28]. Логика рассуждений сводится к следующему: индивиды приходят и уходят, рождаются и умирают, а общество продолжает существовать как некая самодостаточная целостность. Эта традиция берет своё начало в концепции французского социолога Э. Дюркгейма (учеником которого является М. Хальбвакс). Он утверждал, что в понимании закономерностей существования социального организма, целое не сводится к сумме его частей. Целое в данном случае есть некая самостоятельная величина. Общество возвышается над индивидами и не может быть объяснено мыслями и действиями отдельных лиц.

Мы будем исходить из системного подхода, заложенного французским социологом Э. Дюркгеймом, в рамках которого общество рассматривается не просто как совокупность индиви- 
дов, но и как объективная совокупность условий их совместного существования. Он подчёркивал, что общественная жизнь является реальностью особого рода, отличной от природной реальности и несводимой к ней - социальной реальностью. Важной частью этой реальности являются «коллективные представления». Именно они представляют фундамент культуры, которая рассматривается Э. Дюркгеймом как способ организации общественной жизни (это нормы, ценностные ориентации, религиозные представления и др.). Общество как сложная система обладает интегративными свойствами. Одна из главных черт общества - способность к исторически длительному автономному существованию - основана на том, что жизнь общества представляет собой смену поколений. Общества являются самодостаточными системами, способом реализации этой самодостаточности является культура, а её межпоколенная трансляция позволяет обществу воспроизвести себя. Но каждое общество - это сообщество различных локальных образований: классов, страт, слоев, субкультур и т. д. Культура выполняет по отношению к обществу задачи интеграции, консолидации и организации людей; регуляции их совместной деятельности с помощью норм и ценностей. Именно последние особенно значимы для исследователя - в них раскрывается специфика общества. Коллективные представления - это общие идеи и верования, которые связывают людей, формируют социальную ткань бытия человека. Именно культурная память представляет собой способ и форму воспроизводства и закрепления коллективного опыта, который выражается в коллективной памяти как опыте поколений. Коллективные представления исторически связаны с понятиями «празднично-обрядовая культура», «ритуальные практики», «религиозно-мифологические практики». Э. Дюркгейм считал, что истинная цель ритуальных практик - обеспечить выработку базовых коллективных идей внутри собравшейся популяции людей. Без выработки этих базовых коллективных представлений невозможны социальная кооперация и коммуникация. Для Э. Дюркгейма выработка базовых идей есть первичная функция любых религиозных практик во всех религиозно-мифологических системах. А эти идеи образуют необходимое основание для взаимопонимания, а значит для формирования коллективных представлений и соответственно коллективной памяти.

Некоторые современные исследователи, в частности, М. Л. Шуб выражают позицию принципиального несогласия с позицией Э. Дюркгейма и М. Хальбвакса, утверждая, что существует только индивидуальная память как высшая психическая способность человека накапливать и актуализировать информацию [4, с. 7], определяя коллективную память скорее как «метафору», чем строгое научное понятие. Такая позиция вызывает у нас несогласие, так как коллективная память не просто «метафора», это знаково-символический конструкт, создаваемый поколениями на протяжении столетий. Это понимание коллективной памяти во многом базируется на идеях московско-тартусской семиотической школы, представителями которой являются Ю. М. Лотман и Б. А. Успенский. Они ввели в оборот понятие культурная память и определяли культуру как генетически ненаследуемую память коллектива. Ю. М. Лотман пишет о том, что с семиотической точки зрения культура - это надындивидуальный механизм хранения, передачи и выработки новых сообщений (текстов), т. е. коллективная память. Вместе с тем он обращает внимание на то обстоятельство, что любая культура внутренне гетерогенна, то в этом случае можно говорить о сосуществовании в ней «диалектов памяти», отражающих её субкультуры. Культурную память Ю. М. Лотман делит на «информативную» и «креативную» (творческую) [5, с. 674]. Информативная память подчинена линейному движению времени. Для нее значим лишь итоговый текст - конечный результат. Эта память полностью принадлежит настоящему и движется вместе с ним, стирая прошлую информацию как потерявшую актуальность. Здесь хронологически последнее самое ценное и важное. Креативная (творческая память) имеет напротив панхронный характер. В ней окончательно ничто не проходит и не исчезает. Одни тексты временно теряют свою актуальность и передаются на хранение, другие реактивируются. Ю. М. Лотман обращает внимание на специфичность механизмов функционирования культурной памяти. Восприятие текста, его оценка и интерпретация зависит от типа культуры, особенностей пространства времени в котором пребывает реципиент, новых культурных кодов, которые используются для дешифровки и интерпретации текстов. Он отмечает одно из важнейших свойств культурной памяти: «Каждая культура определяет свою парадигму того, что следует помнить (то есть хранить), а что подлежит забвению. Последнее вычеркивается из памяти коллектива и «как бы перестаёт существовать». Но сменяется время, система культурных кодов, и меняется парадигма памяти-забвения. 
То, что объявлялось истинно существующим, может оказаться «как бы не существующим и подлежащим забвению, а несуществовавшее - сделаться существующим и значимым. Античные статуи находили и в доренессансную эпоху, но их выбрасывали и уничтожали, а не хранили. Русская средневековая иконопись была, конечно, известна и в XVIII в., и в XIX в. Но как высокое искусство и культурная ценность она вошла в сознание послепетровской культуры лишь в ХХ в.» [5, с. 675]. Одно из свойств культурной памяти Ю. М. Лотман отмечает как уникальное явление, характеризующее процесс прочтения и извлечения смыслов: циркулирующие в современно-синхронном срезе культуры тексты не только несут в себе смыслы прошлого, но и генерируют новые смыслы. Тексты являются «не складами, а генераторами»[5, с. 675]. Таким образом, существует динамика культурных текстов, которая включает процессы опредмечивания, распредмечивания, объективации, интерпретации текстов, все эти процессы наполняют собой пространство культурной памяти. В этом контексте понятие культурной памяти соотносимо со знаменитым концептом М. М. Бахтина «большое время» культуры.

Близка идеям московско-тартусской школы структура культурной памяти, разработанная Я. Ассманом. Он подчеркивает, что содержание культурной памяти может по-разному структурироваться в зависимости от интересов и видения мира той или иной социальной общностью, в рамках которой создается этот «мемориальный нарратив». Я. Ассман обращает внимание на то обстоятельство, что культурная память «...связывает человека с его современниками, образуя общее пространство опыта, ожиданий и деятельности, чья связующая и обязующая сила устанавливает взаимное доверие и возможность ориентации...включая в сдвигающийся вперёд горизонт настоящего образы и истории иного времени и порождая тем самым надежду и память» [2, с. 15]. В основе этого представления утверждение, что каждая культура образует нечто, что можно назвать «коннективной структурой», а основополагающим принципом данной структуры он называет - «повторение» (связь поколений, преемственность, традицию - авт.). Именно «повторение» «... гарантирует, что траектории деятельности не потеряются в расходящейся бесконечности, а будут подчиняться узнаваемым образцам и опознаваться как элементы «общей культуры» [2, с. 16]. Но «повторение» по Я. Ассману не означает только воспроизводство определенных устоявшихся культурных элементов, образцов, практик и т. д.; процесс гораздо сложнее - наряду с преемственностью он предполагает возможность интепретации и нового прочтения и это неизбежно, так как мы смотрим в прошлое и его оцениваем с позиции опыта, информационного объема и ценностных установок, имеющих место в данном времени и пространстве. А новая интепретация - это новая «коннективная структура»: «Ее связующие силы - не подражание и сохранение, а толкование и воспоминание» [2, с. 17]. Смысл понятия культурная память определяется автором через противопоставление ее коммуникативной памяти. Коммуникативная память, по его мнению, функционирует в горизонте «жизненного мира» (Э. Гуссерль), который детерминирован собственным опытом индивида и доступным для него информационным полем, ее временной диапазон 80 лет. В отличие от неё культурная память относится ко времени «истоков», к далёким временам, настолько далёким, что никто из ныне живущих не может иметь о них никаких личных воспоминаний. Культурная память включает в себя «обосновывающие воспоминания», утверждающие законность и оправданность существующего порядка вещей. Коммуникативная память опирается на непосредственное социальное взаимодействие, в то время как культурная память предполагает устойчивые объективации. Культурная память, в отличие от коммуникативной специально формируется, искусственно оформляется, включается в систему социализации, воспитания, идеологии. Для ее хранения, воспроизводства и трансляции в обществе создаются специальные институты. Культурная память по Я. Ассману - «внешнее измерение человеческой памяти... Со словом «память» ассоциируется в первую очередь чисто внутреннее явление, локализованное в мозгу индивида...Однако содержательное наполнение памяти... определяется в очень большой степени не внутренней вместимостью и контролем, а внешними, т. е. социальными и культурными рамками. На это первым настоятельно указывал Морис Хальбвакс» [2, с. 19].

Разработанная Я. Ассманом концепция позволила обозначить новую область историкокультурологических исследований - изучение «культур воспоминания» различных обществ и их сравнительный анализ. С точки зрения Я. Ассмана прошлое нигде и никогда не передаётся просто от поколения к поколению, а всегда вновь и вновь пересоздается, реконструируется исходя из культур- 
ного и социального опыта, установок, ценностных ориентаций и предпочтений ныне живущих людей. В этом смысле заслуживает внимание идея Ассмана о разграничении категорий «культурная память» и «традиция», так как сложилась практика их сопоставления и рассмотрения почти как идентичных явлений. В этом контексте традиция понимается как форма сохранения и воспроизводства культурного опыта поколений, когда любая интерпретация традиции в пространстве современной культуры может обернуться фактом потери «традиционного» (например, внесение авторских изменений в исполнение «мезенской росписи»), в то время как культурная память живёт и образуется благодаря многочисленным интерпретациям и толкованиям, так как представляет собой не только «факт» прошлого, но и знаково-символический конструкт, созданный настоящим. Как утверждает В. В. Емельянов «...современный человек, дешифрующий старые тексты, неизбежно меняет и собственную систему кодирования и акцентирования информации. Так исторический прогресс и культурная память, начав с противостояния, постепенно вступают в диалог» [6, с. 49].

Таким образом, культурная память понимается нами как знаково-символический конструкт, воплощающий культурный опыт, религиозные практики, образ жизни предшествующих нам поколений, соединяющий в себе два начала-мемориальное и актуальное, протягивающий живую нить, объединяющую воедино прошлое, настоящее и будущее поколений, когда взгляд в прошлое определяется ценностями, идеями установками, которые мы переживаем сегодня. По М. Хальбваксу, культурная память - коллективная память, фактор, объединяющий группу, поддерживающий её идентичность. Места, события, герои объединяют общество, выявляют его сущность и специфику.

В результате анализа наиболее фундаментальных исследований в данной области, можно сформулировать несколько основополагающих положений, обозначающих проблемное поле исследования культурной памяти:

- проблема соотношения индивидуальной и коллективной памяти;

- проблема соотношения индивидуальной, этнокультурной, национальной памяти;

- - проблема понимания культурной памяти как процесса, соответствующего законам культурной динамики: развертывание, воспроизводство, трансформация, видоизменение, забвение и т. д.;

- проблема конструирования культурной памяти в интересах различных социальных групп, в том числе политических групп для достижения определённых целей;

- проблема влияния историко-культурного наследия как духовно-ценностного феномена на смыслы, коммуникации и ценности современной инновационной культуры;

- проблема восприятия культурной памяти как знаково-символического конструкта, образование которого - это новое прочтение памяти о предках, её осмысление и включение в новый пространственно-временной контекст.

Данный перечень проблем мы не представляем как необходимый и достаточный, данная тема нуждается в глубоком межпредметном исследовании. В структуре современной постмодернистской культуры, где доминируют скепсис, ирония, разочарование, моральный релятивизм - в общественном сознании имеет место тенденция обращения к смыслам и образам традиционных культур, что вероятно отражает стремление человека к устойчивости бытия, к освоению культурного опыта предшествующих эпох, к пониманию ценности глубинной связи поколений. Культурная память уникальный способ специфической знаково-символической человеческой деятельности - сохранить прошлое и дать ему новое порождение.

\section{Список литературы}

1. Хальбвакс, М. Социальные рамки памяти / Пер. с фр. и вступ. статья С. Н. Зенкина. - Москва : Новое издательство, 2007. - 348 с. - Текст : непосредственный.

2. Ассман, Я. Культурная память: письмо, память о прошлом и политическая идентичность в высоких культурах древности / Пер. с нем. М. М. Сокольской. - Москва : Языки славянской культуры, 2004. - 368 с. Текст : непосредственный.

3. Дюркгейм, Э. Социология. Её предмет, метод, предназначение / Пер. с фр., составление, послесловие и примечания А. Б. Гофмана. - Москва : Канон, 1995. - 352 с. - (История социологии в памятниках). -Текст : непосредственный.

4. Шуб, М. Л. Социальная, коллективная и культурная память: новый подход к определению смысловых границ понятий. - Текст : непосредственный // Обсерватория культуры. - 2017. - Т. 14, № 1. - С 4-9. 
5. Лотман, Ю. М. Семиосфера. Санкт-Петербург : Искусство, 2010. - 704 с. - Текст : непосредственный.

6. Емельянов, В. В. Исторический прогресс и культурная память (о парадоксах идеи прогресса). - Текст : непосредственный // Вопросы философии. - 2011. - № 8. - С. 46-57.

Olga V. Pervushina, Ph. D. in Cultural Science, Associate Professor Altai State Institute of Culture (Barnaul, Russia) agaki-pervushina@yandex.ru

\title{
CULTURAL MEMORY: PROBLEMATIC FIELDS FOR RESEARCH
}

\begin{abstract}
The paper presents comparative analysis of views of major historians of culture, sociologists, semiologists, cultural specialists of Russia and Europe of the $19^{\text {th }}$ and $20^{\text {th }}$ centuries on cultural memory phenomenon which is considered as sustainable feature of social life, a specific symbolic construct with its own structure, laws of dynamics, mechanisms of selection. The author describes dominant approaches in humanitarian and social sciences to understanding a concept "cultural memory", clears up an issue about its correlation with definitions "individual memory" and "collective memory". Also, the paper lists the key areas for scientific research in cultural memory phenomenon that require scholars' attention.

Key words: cultural memory, collective memory, individual memory, a cultural tradition, succession, traditional culture, a symbolic construct, a text.
\end{abstract}

УДК 069:001.89:719 (571.14-25)

DOI: 10.32340/2414-9101-2019-2-38-43

Н. Н. Покровский, кандидат исторических наук Институт истории Сибирского отделения Российской академии наук

(Новосибирск, Россия) pokrov@li.ru

О. Н. Шелегина, доктор исторических наук Институт истории Сибирского отделения Российской академии наук (Новосибирск, Россия) oshelegina@yandex.ru

Г. М. Запорожченко, доктор исторических наук Институт истории Сибирского отделения Российской академии наук

(Новосибирск, Россия) galinakoop@yandex.ru

\section{ДОСТОПРИМЕЧАТЕЛЬНОЕ МЕСТО «НОВОСИБИРСКИЙ АКАДЕМГОРОДОК» - СОЦИОКУЛЬТУРНЫЙ РЕСУРС МЕГАПРОЕКТА «АКАДЕМГОРОДОК 2.0»}

Аннотация. Охарактеризован исторический контекст появления в 1957 г. первого в Сибири наукограда (технополиса) - Новосибирского Академгородка - c инновационной научноисследовательской, научно-производственной, образовательной, культурно-досуговой и бытовой инфраструктурой. Представлены результаты авторских исследований в области конвертации исторического опыта в ресурс конструирования устойчивой идентичности личности и социальных групп; изложена аргументация в пользу применения к Новосибирскому Академгородку концепта «научный monoc», рассматриваемого авторами в качестве одной из разновидностей регионально-локальной идентичности. Представлены авторские соображения о потенциале внедрения в грантосоискательские, социально-культурные, информационно-коммуникационные и образовательные практики методик выявления и презентации социокультурных комплексов достопримечательных мест, изложенные в научно-популярном издании Института истории Сибирского отделения Российской академии наук (Новосибирск, Россия) «Достопримечательное место “Новосибирский Академгородок”: научное и историко-культурное наследие» (Новосибирск, 2019). 